\title{
The United States Postal Service: an Essential Public Health Agency?
}

\author{
Syed M. Qasim Hussaini, MD, $\mathrm{MS}^{\top}$ (1) and G. Caleb Alexander, MD, $M S^{2,3,4}$
}

${ }^{1}$ Sidney Kimmel Comprehensive Cancer Center, Johns Hopkins Medicine, Baltimore, MD, USA; ${ }^{2}$ Department of Medicine, Johns Hopkins Medicine, Baltimore, MD, USA; ${ }^{3}$ Center for Drug Safety and Effectiveness, Johns Hopkins Bloomberg School of Public Health, Baltimore, MD, USA; ${ }^{4}$ Department of Epidemiology, Johns Hopkins Bloomberg School of Public Health, Baltimore, MD, USA.

$\mathrm{J}$ Gen Intern Med 35(12):3699-701

DOI: $10.1007 / \mathrm{s} 11606-020-06275-2$

(c) Society of General Internal Medicine 2020

$\mathrm{O}$ n August 7, 2020, the United States Postal Service (USPS) announced cost-cutting measures and leadership changes to reorient core aspects of the service and to improve efficiency. Considerable debate has since ensued regarding whether, how and when these changes should be implemented, in part due to concerns about potential voter disenfranchisement during the upcoming national election. ${ }^{1}$ Deliberation regarding these matters, while essential in its own right, also provides an opportunity to consider the broader role of the USPS as a public health agency.

\section{MAIL-ORDER PHARMACY}

Over the past few decades, there has been significant growth in the use of mail-order pharmacy, with more than one-fifth of US retail prescriptions, or more than 1.2 billion prescriptions, delivered by mail in 2019. In a recent analysis, $17 \%(7.3$ million) of Medicare Part D beneficiaries in 2018 had at least one medication delivered through a mail-order pharmacy, use of which was more common among women and for cardiovascular medications. ${ }^{2}$ Such use, which is associated with both greater convenience and medication adherence, was initially pioneered by the Veterans Administration (VA), the largest integrated health care system in the USA; approximately 80 $90 \%$ of medicines that the VA provides for its 9 million veterans and their families each year are delivered by US mail. While millions of Americans benefit from the security and convenience of mail-order pharmacy, these services are especially important for vulnerable groups such as homebound elderly and individuals with chronic conditions, including diabetes, asthma, and congestive heart failure, where failure

Received September 14, 2020

Accepted September 25, 2020

Published online October 2, 2020 to refill medications often triggers the use of more expensive and less efficient ambulatory or inpatient care. This is especially true during a pandemic, when many high-risk patients may otherwise forgo care due to increased risks associated with COVID-19 exposure. Early reports in the media have noted delays in mail-order refills to veterans during this time.

\section{MAIL-IN BALLOT VOTING}

In 2016, 33 million ballots, or one-fourth of all votes in the federal election, were cast by mail, and in the midst of the COVID-19 pandemic, mail-in ballot voting also offers a means to safely reduce individuals' potential exposure to coronavirus infection. Upcoming elections are expected to see a record mail-in ballot voter turnout with a two- to threefold increase over previous national elections. While wait times for in-person voting have decreased during the past fifteen years and averaged 19 minutes in 2016, close to 3 million or more Americans waited 30 minutes or more in line to cast a vote in 2018 with the African-American and nonwhite communities seeing disproportionately longer wait times. ${ }^{3}$ These have raised concerns about potential COVID19 exposure as well as voter disenfranchisement among individuals who, as a result, decide not to vote. It is unclear to what degree polling stations will be able to adapt their policies and practices to minimize the potential risks to those casting inperson votes, and it is also noteworthy that areas with historically longer wait times have tended to be areas with underserved populations at greater risk of COVID-19 infection and mortality. ${ }^{4}$

\section{NATIONAL EMERGENCY PREPAREDNESS}

In 2019, the USPS included 31,000 post offices and delivered 143 billion pieces of mail from Alaska to Florida, including mail to 46 million rural addresses, many unreachable by private mail services. It is one of the largest retail networks in the country - and one of the largest infrastructures and civilian fleets in the world. Because of its broad reach and established infrastructure, the USPS also plays a key role in initiatives to ensure national emergency preparedness in response to natural disasters, pandemics, and bioterrorism. In 
2005, this function was exemplified after more than 1 million individuals were displaced from Hurricane Katrina, the costliest natural disaster in US history. During the recovery effort, the USPS's infrastructure helped to re-establish communication and commerce channels, deliver medicines, and provide relief checks to displaced citizens. ${ }^{5}$ Similarly, the USPS features in the Centers for Disease Control and Prevention's Cities Readiness Initiative that includes public health emergency plans for 72 American cities housing $60 \%$ of the population, as well as the federal government's National Response Framework and National Infrastructure Protection Plans, both of which rely upon the USPS to help provide unified national plans to natural disasters, bioterrorism, and pandemics.

\section{WORKFORCE OF CARRIERS AND OTHER EMPLOYEES}

Since the Civil War and passage of a congressional law that ended a white-only hiring practice, and end of further discriminatory hiring practices in the early twentieth century, the Postal Service has established a reputation for equal employment opportunities to generations of African-Americans through a history of secure middle-class jobs. Today, the opportunities that the USPS has to impact public health arise from its role as the second largest civilian employer in the country, employing 630,000 employees, of which $40 \%$ are women and $40 \%$ are people of color. It employs close to 100,000 military veterans, second only to the Department of Defense. As a federal agency, it leads with respect to employee health and wellness and employs a diverse and trusted workforce, a majority of whom are currently working at the nation's frontlines in delivering mail during a pandemic.

\section{ENGAGEMENT AND CONTACT}

In addition to the hundreds of millions of prescriptions that the USPS distributes, many individuals also rely upon the USPS as a source of other important health care information, ranging from feedback on recent laboratory work or clinical imaging to visit summaries and information about follow-up appointments for chronic conditions. USPS letter carriers also traverse the same routes, often over years or even decades, and may develop close relationships with their mail patrons; through the Carrier Alert program, USPS helps to monitor the health of elderly and disabled mail patrons on their route, and carriers may be instrumental in bringing timely medical or emergency help. ${ }^{6}$

\section{PANDEMIC IMPACT ON USPS}

For years, the USPS has been scrutinized for continued loss of revenue, the result of competition from private carriers, reduction in first-class mail and failure to modernize. The USPS has also been strained by provisions in the Postal Accountability and Enhancement Act of 2006 requiring it to fund postretirement health benefits 75 years into the future. The pandemic has only made these matters worse. While mail volumes have declined, package volumes have increased, leading to increased short-term revenue but also taxing daily operations at the agency. The recent removal of mail sorting machines has heightened concerns, and there have been reports of slower delivery of mail-order medicines to veterans, as well as delays in all mail delivery. ${ }^{7}$ Such changes have resulted in ongoing discussions in the legislature and the public about the future of the agency. On August 18, the Postmaster General testified in Congress and the USPS has released statements since expressing confidence in its ability to deliver mail-in ballots and halting any further operational changes until after the election.

\section{LOOKING FORWARD}

The sonic eagle of the USPS is ubiquitous in cities, towns, and rural communities across the country. First founded in 1775 as a self-funded and independent agency under the Department of Treasury, the Postal Service Act of 1792 subsidized newspaper circulation in an effort to create an informed electorate. It has since contributed to the spread of new ideas, literacy, and economic growth across the nation. It has also weathered world wars, political upheaval, and major structural reorganizations, most recently as part of the Postal Reorganization Act of 1970. While the USPS has met recent challenges, it supports the American public in more ways than one with its breadth of services and well-established infrastructure. These motivate the desire for reform that should be informed by, and safeguard, the important public health functions of one of the country's oldest federal agencies.

Corresponding Author: G. Caleb Alexander, MD, MS; Department of Epidemiology, Johns Hopkins Bloomberg School of Public Health, Baltimore, MD, USA (e-mail: galexan9@jhmi.edu).

\section{Compliance with Ethical Standards:}

Conflict of Interest: Dr. Alexander is past Chair of FDA's Peripheral and Central Nervous System Advisory Committee; has served as a paid advisor to IQVIA; is a co-founding Principal and equity holder in Monument Analytics, a health care consultancy whose clients include the life sciences industry as well as plaintiffs in opioid litigation; and is a member of OptumRx's National P\&T Committee. This arrangement has been reviewed and approved by Johns Hopkins University in accordance with its conflict of interest policies.

\section{REFERENCES}

1. U.S. Postal Service letters to state. Washington Post. Available at: https:// www.washingtonpost.com/context/u-s-postal-service-letters-to-states/ b50799f2-25ad-40ed-bale-9d648b1814ad/?itid=lk_interstitial_manual_6 (Accessed Aug 22, 2020).

2. Cubanski, Biniek JF, Rae M, Damico A, Frederiksen B, Salganicoff A. Mail Delays Could Affect Mail-Order Prescriptions for Millions of Medicare Part D and Large Employer Plan Enrollees. Kaiser Family Foundation. 2020. Available at: https://www.kff.org/coronavirus-covid-19/issue-brief/ mail-delays-could-affect-mail-order-prescriptions-for-millions-of- 
medicare-part-d-and-large-employer-plan-enrollees / (Accessed August 21, 2020).

3. Klain H, Morris K, Feldman F, Ayala R. Waiting to Vote: Racial Disparities in Election Day Experiences. Brennan Center for Justice at New York University School of Law. 2020. Available at: https://www.brennancenter. org/our-work/research-reports/waiting-vote\# (Accessed August 21 , 2020).

4. Chen MK, Haggag K, Pope DG, Rohla R. Racial Disparities in Voting Wait Times: Evidence from Smartphone Data. National Journal of Economic Research. 2019. NBER Working Paper \#26487. Available at: https://www. nber.org/papers/w26487 (Accessed August 21, 2020).

5. The contribution of the postal service in national emergencies: A Case Study of its Role in Katrina and its Emergency Preparedness Efforts. 2011. Joy Leong Consulting, LLC, for Postal Regulatory Commission. Available at: https://www.prc.gov/sites/default/files/archived/Emergency_Prep_ Report.pdf (Accessed August 21, 2020).
6. National Association of Letter Carriers. Carrier Alert: Your neighborhood letter carrier wants to help you. Available at: https://www.nalc.org/ community-service/carrier-alert (Accessed August 21, 2020).

7. Frankel TC. Postal problems could continue despite suspension of policies blamed for mail delays: Slow mail and political warefare - and the pandemic - have thrown the agency into crisis. Washington Post. August 19, 2020. Available at: https://www.washingtonpost.com/business/ 2020/08/19/postal-problems-could-continue-despite-suspension-policies-blamed-mail-delays/ (Accessed August 21, 2020).

Publisher's Note: Springer Nature remains neutral with regard to jurisdictional claims in published maps and institutional affiliations. 